\title{
Advanced Wear Simulation for Bulk Metal Forming Processes
}

\author{
Bernd-Arno Behrens ${ }^{1}$, Anas Bouguecha ${ }^{1}$, Milan Vucetic ${ }^{1}$, Alexander Chugreev ${ }^{1, a}$ \\ ${ }^{1}$ Institute of Forming Technology and Machines (IFUM), Leibniz Universität Hannover, 30823 Garbsen, Germany
}

\begin{abstract}
In the recent decades the finite element method has become an essential tool for the cost-efficient virtual process design in the metal forming sector in order to counter the constantly increasing quality standards, particularly from the automotive industry as well as intensified international competition in the forging industry. An optimized process design taking precise tool wear prediction into account is a way to increase the cost-efficiency of the bulk metal forming processes. The main objective of the work presented in this paper is a modelling algorithm, which allows predicting die wear with respect to a geometry update during the forming simulation. Changes in the contact area caused by geometry update lead to the different die wear distribution. It primarily concerns the die areas, which undergo high thermal and mechanical loads.
\end{abstract}

\section{Introduction}

In bulk metal forming industry the tooling and setup costs amount primarily from 5 to $15 \%$ of the total production costs depending on the process type [1]. In the case of precision forging they can even arise up to $35 \%$ [2]. In this context virtual tool life estimation is gaining importance in the recent years. In addition, new challenges in the bulk metal forming industry are highstrength materials, trends for the near net shape production and increasing performance of the forming machines. High strength of the formed material and short cycle times are tightly related to the prevailing contact pressures and thus to the die load and its failure.

Numerous factors including plastic deformation, thermal and mechanical fatigue affect the die service life during sheet [3] and bulk [4] metal forming. Extensive investigations on the tool life in hot forging processes have shown that more than $70 \%$ of tool failure is caused by the die wear [5]. In this context precise evaluation of die wear can help to avoid an improper tool design already at early development stages. On the other hand, it can also significantly contribute to improve the current tool geometry and thus the cost-efficiency of the forming process.

\section{Theory}

\subsection{Conventional modelling of die wear}

Wear is described as a progressive loss of material from the surface caused by a mechanical action of the opposite contact body [6]. To allow a realistic prediction of the tool wear during metal forming processes, research works have been carried out by several authors to estimate the die wear experimentally as well as numerically.

The most widely used models for die wear prediction are based on the Eq. 1 provided by Archard [7]. Archard has defined the wear volume $(W)$ as a function of load on the contact area $(P)$, relative sliding distance $(L)$, local surface hardness of the wearing material $(H)$ and wear coefficient $(k)$ :

$$
W=k \frac{P L}{H}
$$

Relative movements between the forming tool and the formed material during hot forging occur in combination with thermal loads and high contact pressures acting at the die surface simultaneously. These factors are being variously superimposed during the forming process and lead to a pronounced die wear, which differs by a location.

Doege et al. [8] have used Archard's equation in a commercial finite element code for the analysis of die wear in a precision hot forging process, taking pressure dependent heat transfer into account. Due to complexity of the occurring microstructural and tribological effects, not all process-specific factors have been taken into account. Behrens [9] has improved the Eq. 1 by extending it with a temperature and time dependence of the tool surface hardness (Eq. 2).

$$
\dot{w}=k \frac{\sigma_{N}}{H(\vartheta, t)} v_{r e l} \quad \text { on } \quad \partial \Omega^{t o o l}
$$

In this equation the normal velocity of tool wear $\dot{w}$ is defined as a product of normal contact $\operatorname{stress} \sigma_{N}$, relative sliding velocity $v_{r e l}$ and is inverse proportional to the current die surface hardness $H(\vartheta, t)$. Through

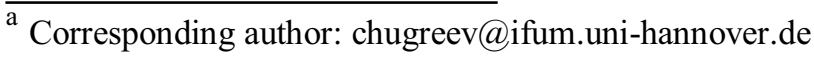


adjusting the wear coefficient $k$ in the equation (2) the results have shown a good qualitative agreement with experimental data for different forming processes, e. g. for hot extrusion [10] and hot forging [9]. In an earlier work Behrens et al. [11] have extended the equation (Eq. 1), in order to take tangential friction stress component into account. However, determination of the wear coefficient is an extremely time- and cost-consuming procedure. In addition, the coefficient obtained is mostly bound to a particular hot forging process. Thus the classical wear simulation can mainly be used for a qualitative analysis to detect some critical areas or to compare different tool designs [12].

\subsection{Advanced Algorithm for Wear Prediction}

According to Hoffmann [12], the wear rate does not undergo a linear propagation. In general, wear rate is changing through three different stages: early run-in period with instable wear rate, middle stage with stable low wear rate and the third stage which is characterized by accelerated wear (Fig. 1).

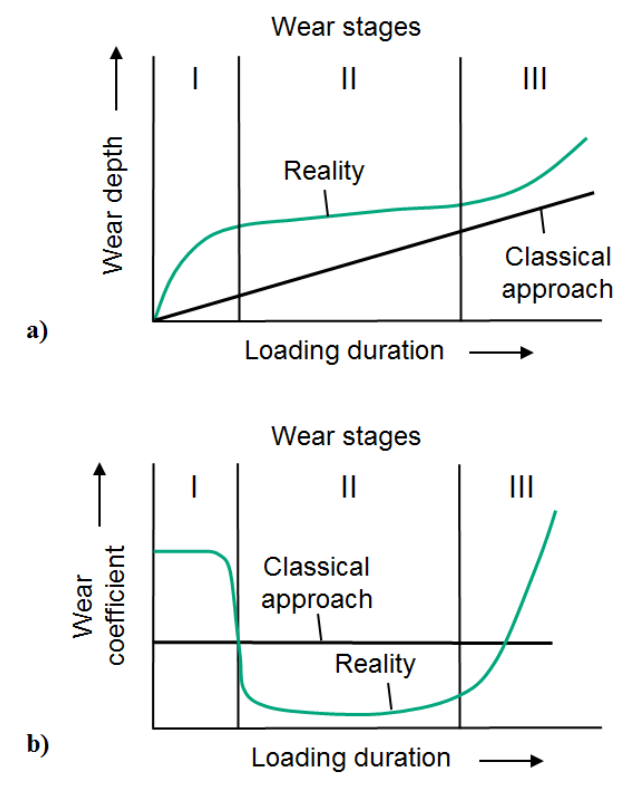

Figure 1. Three stages of wear progression: illustrated on wear coefficient (top) and on wear depth (bottom) (Based on [12]).

In addition, the tool geometry varies over the production time due to wear and plastic deformation, changing the contact area and thus the local stress state in the active contact zone. The effect of plastic deformation decreases with increasing amount of forging cycles [5]. Hence, the effect of tool wear is crucial for the tool design especially in high-volume serial production [13]. For this purpose several researches have been carried out to observe the effect of updating the geometry due to the tool wear [14, 15]. Hoffmann et al. [16] have shown that the geometry update scheme significantly affects the die wear prediction in cold sheet metal forming, which then leads to more realistic results. Considering these effects, a more realistic quantitative estimation of the tool wear can be performed.

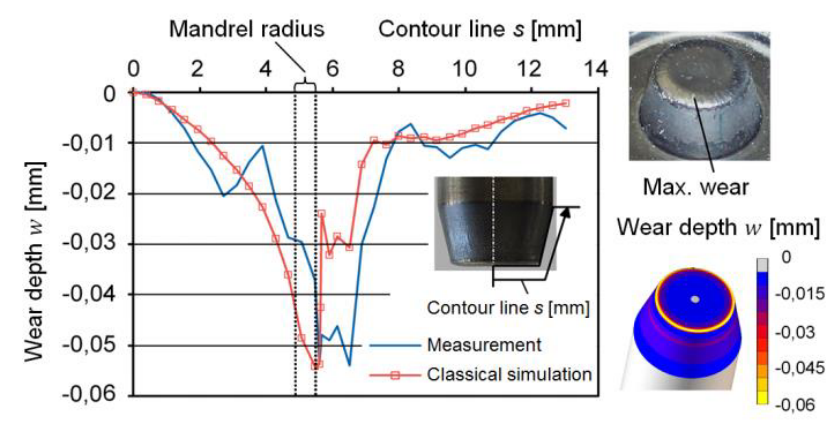

Figure 2. Comparison of measured and simulated wear profiles at the die mandrel after 2,000 forging cycles: with classical simulation algorithm [9].

As shown in Fig. 2, the die wear calculated with the classical approach is concentrated locally at the mandrel radius. However, the real tool material at the sharp die radius gets worn and thus, the contact pressures and the resulting wear gets resolved in its vicinity, making the area with the highest wear at the sharp die radius more extended contrary to the computed one. Besides, worn tool geometry affects the final shape of the formed material. To maintain tight tolerances over the whole tool service life it is also important to have a reliable simulation tool for quantitative die wear prediction. In order to take changes of the worn tool geometry into account an iterative algorithm as shown in Fig. 3 was developed.

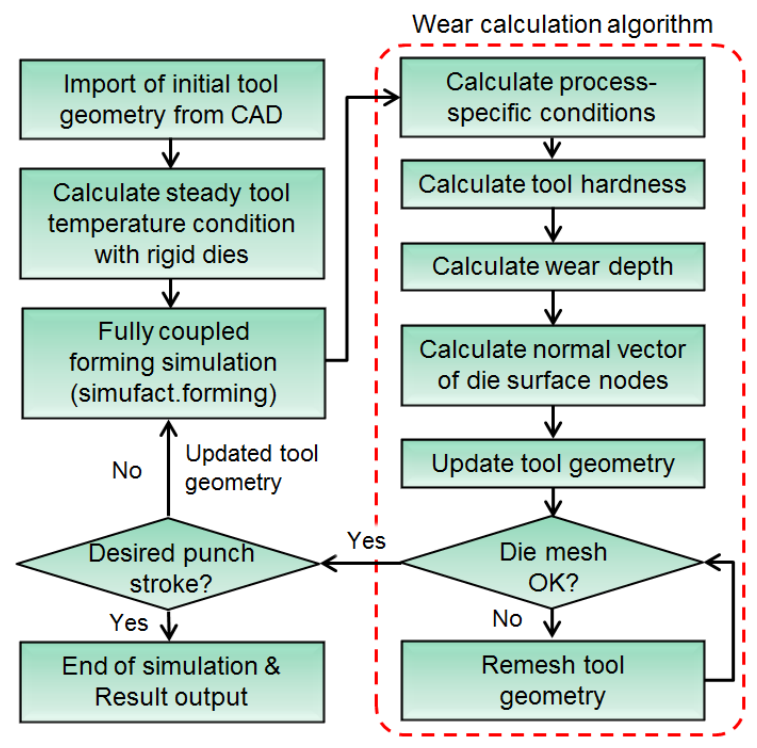

Figure 3. Shortened flowchart of the simulation algorithm involving tool wear estimation with geometry update.

In order to implement the geometry update algorithm, a fully coupled forming simulation intending the calculation of the steady state of tool temperature distribution is to be carried out at first. After that, absolute incremental values of the local wear depth are computed accordingly to Eq. 2 for each tool node which comes in contact with the workpiece. Finally, the affected tool nodes are moved in the normal direction out of the contact body (workpiece) at a distance equal to the calculated tool wear depth increment. 


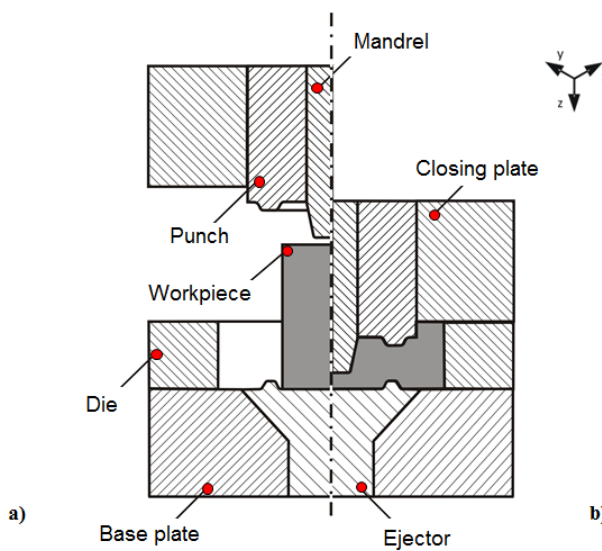

Figure 4. Schematics of the considered precision forging process: (a) tooling system, (b) scheme of the used FE-Model and (c) plastic strain contour in the forged part.

It must be noted, that for the wear prediction with the geometry update scheme it is still vital to employ an experimentally validated wear coefficient $k$, i.e. using the experimental results shown in Fig. 2, in order to calculate the absolute values of the wear depth for the subsequent node displacement algorithm. Due to possible node displacements during the wear calculation algorithm die elements can be distorted or turn inside out, thus an additional remeshing step for tool geometry has been included in the simulation algorithm.

\section{Application}

In order to verify whether the geometry update algorithm has any significant deviation from the conventional wear prediction scheme, both of these algorithms were employed in the FE simulation of a precision hot forging process (Fig. 4).

The investigated process was analysed with a nonlinear implicit FE-solver of Simufact.forming. Workpiece was modelled with quadrilateral elements having elastic-viscoplastic material behaviour of typical medium-carbon steel (DIN 1.0503). The forming temperature of the raw part is $1200{ }^{\circ} \mathrm{C}$. Non-uniform initial temperature of the forming tools as considered in [5] was assumed.

The forming tools are modelled as heat conducting deformable bodies which can undergo elastic deformation during the forming process. Surface hardness of the dies is computed based on the nodal temperature and amount of forging cycles, as discussed in [9]. Particular attention needs to be paid to modelling of friction [17] as well as heat transfer [18] behaviour during the hot forging processes. The combined Coulomb-Tresca model with a friction coefficient of 0.1 and the friction shear factor of 0.4 based on the work done by Jeong et al. [19] has been used in the simulation. Since, the authors have already broadly investigated this process in the previous work, the other simulation parameters such as heat transfer coefficients, film coefficients to environment etc. as well as experimental data were extracted from [5]. In order to decrease computation time, the full process was modelled in accordance with the rotational symmetry of the workpiece.

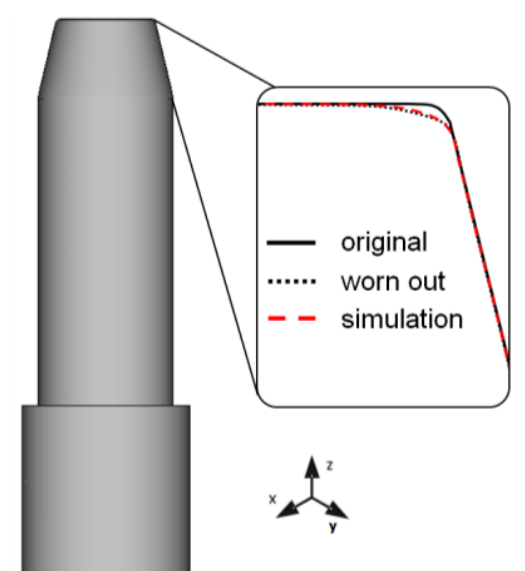

Figure 5. Facing of original, worn out and simulated geometries of the mandrel after 2000 forging cycles: advanced simulation algorithm (based on [5]).

As shown in the Fig. 5, significant deviation in the tool geometry can occur depending on the processspecific conditions as well as on the amount of forging cycles of the respective processes.

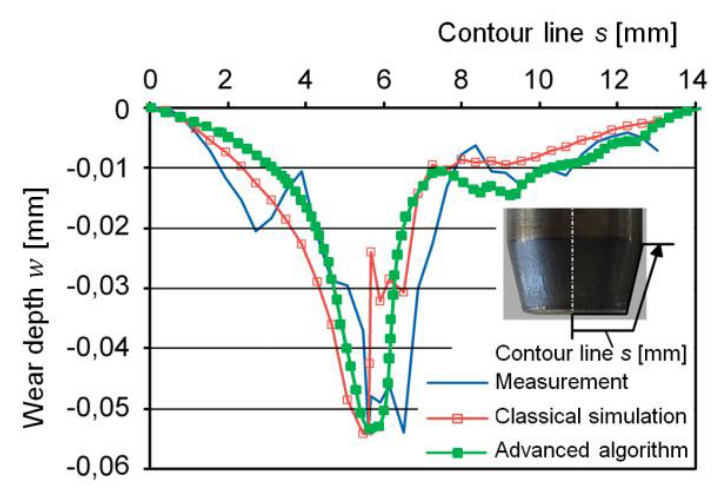

Figure 6. Comparison of measured and simulated wear profiles at the die mandrel after 2,000 forging cycles: with advanced simulation algorithm.

Furthermore, changes in the tool geometry influence the effective contact area and thus the occurring contact stresses. This effect is especially evident on the high loaded die areas, such as the die radius. Therefore, deviations of the tool geometry as well as changes in the contact pressure distribution result in a different tool wear 
progress compared to the conventional simulation scheme (Fig. 6). The most significant contrast arises at the die areas which undergo high thermal and mechanical loads such as the die radius in the investigated process.

\section{Conclusions}

Optimized process design taking tool wear into account is an effective way to extend the life of forming dies and thus the economics of the forming process. For this purpose, an advanced simulation algorithm taking tool geometry deviations into account has been proposed in this paper. In addition to the temperature-dependent tool hardness and elastic die deformation, tool geometry update caused by die wear has been integrated in the wear prediction algorithm. Due to the arising geometry changes, tool mesh can become distorted. Thus a special remeshing step for tool mesh has been also incorporated. Furthermore, tool wear of the discussed hot forging process was investigated numerically with the means of the introduced algorithm.

The conducted investigations have shown a strong contrast in comparison to the results computed using the conventional simulation scheme, especially at the high loaded die areas. Particularly, for the case of precision forging it is vital to provide reliable tool wear estimation for high loaded die areas. In the further works authors would like to extend the presented computational model by considering complex stress states, more complicated tool geometries and to calibrate the model based on the experimental results from the other forming processes. Due to the fact that plastic tool deformation can occur at such high forging temperatures, but the use of plastically deformable dies will crucially increase the computation time and make the simulation inefficient for industrial process design, the used method for tool wear prediction should be further developed in order to consider the plastic deformation of tools. Furthermore, progressive nature of the wear coefficient, die fatigue due to the crack formation as well as microstructure phenomena at the tool surface will be the subjects of future works.

\section{Acknowledgments}

The authors wish to express sincere thanks to the German Research Foundation (DFG) for supporting the project T12 "Beschichtungen als Verschleißschutz für Werkzeuge der Warmmassivumformung" within the scope of the collaborative research center 489 (SFB 489). Moreover, the authors are very grateful to the Simufact Engineering $\mathrm{GmbH}$ for their kind support and conducive discussions.

\section{References}

1. M. Knörr, Auslegung von Massivumformwerkzeugen gegen Versagen durch Ermüdung, Springer Verlag (1996)
2. R. Geigert, R. Balbach, Neue Einsatzbereiche durch erhöhte Präzision, Fertigungstechnisches Kolloquium 85, pp. 92-103 (1985)

3. E. Doege, Maschinen fur die Warmumformung und Blechformung. 9. Umformtechnisches Kolloquium, pp. 155-167 (1977).

4. M. Shirgaokar, Ph. D. Thesis (2008)

5. B.-A. Behrens, F. Schaefer, J. Mat. Proc. Tech., 167, pp. 309-315 (2005)

6. E. Rabinowicz, Friction and Wear of Materials, John Wiley and Sons (1995)

7. J. F. Archard, Wear Theory and Mechanism, Wear Control Handbook, ASME, New York, pp. 35-80 (1980)

8. E. Doege, H. Naegele, U. Schliephake, Proceedings of the Institution of Mechanical Engineers, 280, pp. 111-119 (1993)

9. B.-A. Behrens, CIRP Annals - 57, pp. 305-308 (2008)

10. A. Groseclose, C. Choi, J. L. Gonzalez-Mendez, T. Altan, Estimation of Die Stresses and Wear in Warm Forging of Steel Pinion Shafts (2009)

11. B.-A. Behrens, A. Bouguecha, M. Vucetic, A. Chugreev, D. Rosenbusch, ESAFORM 2016 Proceedings (2016, accepted)

12. K. Ersoy, M. Labermeyer, Verschleiß sicher vorhersagen, Blech InForm, 3 (2007)

13. B.-A. Behrens, A. Bouguecha, T. Hadifi, A. Klassen, Key Eng. Mat., 504-506, pp. 163-168 (2012)

14. M. Oqvist, Wear, 249, pp. 6-1 (2001)

15. C. Wang, J. Chen, Int. J. Adv. Man. Tech., 69, pp. 797-803 (2013)

16. H. Hoffmann, C. Hwang, K. Ersoy, CIRP Annals Man. Tech., 54, pp. 217-220 (2005)

17. B.-A. Behrens, A. Bouguecha, T. Hadifi, J. Mielke, Prod. Eng. Res. Devel., 5, pp. 621-627 (2011)

18. B.-A. Behrens, A. Bouguecha, I. Lüken, J. Mielke, M. Bistron, Tribology in Hot Forging, Comprehensive Materials Processing, 5, pp. 211-234 (2010)

19. D. J. Jeong, D. J. Kim, J. H. Kim, B. M. Kim, T. A. Dean, J. Mat. Proc. Tech., 113, pp. 544-550, (2001). 